\title{
Los Estudios Generales, punto de apoyo para re-mover la democracia actual ${ }^{1}$
}

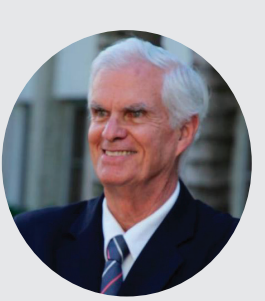

Fernando I. Ferrán*

Pontificia Universidad Católica Madre y Maestra (PUCMM)

f.ferran@ce.pucmm.edu.do

General studies, fulcrum to re-move the current democracy

Recibido: 9 de octubre de 2021 | Aprobado: 24 de noviembre de 2021

\section{Resumen}

Este escrito sustenta que los estudios iniciales en las universidades del hemisferio americano son el punto de apoyo indispensable para humanizar el 'subiectum' de todos sus estudiantes y, así, promover el ejercicio responsable de ciudadanía democrática. Para ello, procede metodológicamente de un diagnóstico sucinto del mundo político y entonces analiza de manera contrastante la relación existente entre esa realidad y el modelo universitario vigente en la región. La conclusión de la pesquisa establece cuál es el papel instrumental del nivel universitario propedéutico en tanto que orientado a formar al sujeto humano y transformar el quehacer político de nuestras pretendidas sociedades democráticas in fieri.

Palabras clave: Universidad, ciudadanía, democracia, subjetividad, enseñanza

\section{Abstract}

This writing sustains that the initial studies in the universities of the American hemisphere are the indispensable point of support to humanize the "subiectum" of all its students and, thus, promote the exercise of democratic citizenship. To do this, he methodologically proceeds from a succinct diagnosis of the political world and then analyzes the relationship between that reality and the current university model in the American region. The conclusion of such research establishes what is the instrumental role of the preparatory university level as oriented to train the human subject and transform the political work of our so-called democratic societies in fieri.

Keywords: University, citizenship, democracy, subjectivity, education

1 Ensayo presentado como una de las ponencias en junio de 2021 en el XII Simposio Internacional de Estudios Generales (modalidad virtual). Pontificia Universidad Católica Madre y Maestra (PUCMM), República Dominicana, y Red Internacional de Estudios Generales (RIDEG). Además, fue publicado en ACENTO en octubre 2021. Esta versión actual ofrece nuevas conclusiones.

* Licenciado en Filosofía por la UCMM en Santiago, con estudios de maestría y doctorado en antropología social y filosofía, en las universidades Loyola, de Chicago, y Lovaina, Bélgica. Actualmente se desempeña como investigador y profesor de la PUCMM y director del Centro de Estudios Económicos y Sociales P. José Luis Alemán. Para contactar al autor: f.ferran@ce.pucmm.edu.do

ISSN (en línea): 1814-4152 / Sitio web: http://cuaderno.pucmm.edu.do

Cómo CITAR: Ferrán, F. (2022). Los Estudios Generales, punto de apoyo para re-mover la democracia actual. Cuaderno de Pedagogía Universitaria, 19 (37), 19-30. 


\section{Introducción}

Inicio este ensayo declarando su tesis central y la cual considero una verdad incontrovertible: La gran mayoría de las universidades del hemisferio americano ofrecen estudios iniciales, considerados en algunos escenarios como un ciclo básico y en otros como estudios generales. La valía de este espacio propedéutico se logrará en la medida en que pueda constituirse como el punto de apoyo indispensable y eficaz para humanizar el 'subiectum' de todos y cada uno de sus estudiantes y, así, solo así, remover y promover, tanto el bienestar de la población, en general, como en particular, la cultura, el régimen y el ejercicio de ciudadanía democrática de nuestras respectivas sociedades.

Luego de declarar la tesis, a seguidas, me limitaré a exponer el hilo conductor de dicha afirmación. Ante todo, primero, diagnostico la realidad política de los pueblos del hemisferio americano; a saber, la democracia de los idiotas'. Claro está, no con la connotación con la que actualmente puede interpretarse el término de idiota, sino, -solo y exclusivamente- en su acepción griega: "En Grecia ser un ciudadano de una polis libre y no participar en la vida política de la ciudad era considerado tabú. Esto es así, ya que significaba a cierto modo que a pesar de ser libre, prefería que su vida fuese manejada por otros, relegando su derecho básico como ciudadano a la representación. A estas personas se las denominaba i̊ı $\iota^{\prime} \tau \eta \varsigma$, idiōtēs ${ }^{1}$, lo cual significaba en cierta medida un ciudadano privado inactivo".

Esa sonografía -más que radiografía diagnósticaantes descrita podría llevarnos a cuestionar qué tiene que ver la realidad política con el modelo universitario imperante en las américas. De esta manera, en segundo lugar, pretendo articular el ciclo inicial con en esa desarticulada realidad democrática. Y, por ende, en tercer lugar, defenderé el papel instrumental, no de la universidad en general, sino de su momento propedéutico, para formar al sujeto humano y transformar el quehacer político de nuestras pretendidas sociedades democráticas.
Estoy seguro de que solo a través del discurso humano es que nos sensibilizamos, es decir, nos hacemos conscientes y volitivamente mejores como ciudadanos en la práctica, sin embargo, es evidente que la educación contemporánea -preocupada por su salud financiera- en lo que termina es atiborrando a cada profesional in fieri de datos e información. Entonces, la pregunta a responder es y sigue siendo, ¿cuál es el valor instrumental de los estudios iniciales de nuestras universidades en el contexto de la modalidad democrática implementada por doquier?

Para responder esta interrogante como eje fundamental de este ensayo, propongo como objetivo mostrar que los estudios iniciales en las universidades del hemisferio americano son el punto de apoyo indispensable para humanizar el 'subiectum' de todos sus estudiantes y, así, promover el ejercicio responsable de ciudadanía democrática. Este ensayo no pretende ofrecer verdades inamovibles, sino promover la discusión sobre el tema, así que es posible que aparente un cuadro en blanco y negro, sin matices de grises.

\section{Problema: la ineptocracia política de los "idiotas"2}

a. Sociedades democráticas. Todas las sociedades del hemisferio americano -para no ir más lejos en el alcance de esta exposición- son calificadas por sí mismas o por sus vecinas de democráticas. En ninguna se habla -a lo Maquiavelo (1999)- del gobierno del poder, por el poder y para el poder del Príncipe. Ni siquiera en los regímenes tenidos de dictatoriales o autoritarios, ellos se reconocen como antidemocráticos, opresores, despóticos o tiránicos.

Al contrario, el conjunto de ellos, así como en particular todos los gobiernos americanos, se acogen a alguna variante de la definición original de Tucídides en Atenas - de acuerdo a la cual el régimen ateniense de hombres libres y con propiedades era democrático porque el gobierno y sus leyes dependían de la mayoría y no de la minoría de esos mismos ciudadanos; o, en su transcurrir histórico, se

1 Ver, https://www.anfrix.com/2007/02/ser-un-idiota/ ; http://etimologias.dechile.net/?idiota

2 Ver supra la aclaración sobre el término 
atienen a la fórmula del presidente estadounidense Lincoln y por eso el mundo político y su narrativa están hoy día revestidos de democracia entendida como el gobierno del pueblo, por el pueblo y, claro está, aunque muchos lo duden, para el pueblo.

Hasta ahí todo está más o menos claro. La cuestión se complica al analizar la modalidad de esas tantas democracias.

b. Gobiernos e idiotas. Los pueblos, ninguno de nuestros pueblos, tienen los gobernantes que se merecen, sino los que se le parecen. Votamos por representantes, no por líderes. Las consecuencias las publicitan las encuestas e investigaciones: solo en la América latina el 50\% y en la RD el 68\% de la población no le importaría tener gobiernos no democráticos, de acuerdo con el último informe de Desarrollo Humano del PNUD (Mejía 2021). En verdad, afirman preferir vender su herencia democrática por gobiernos autoritarios, pero más eficaces. De esa manera, en la actualidad solo contamos con democracias electorales fruto legítimo de regímenes políticos calificados de presidencialistas y revestidos de un estado de ánimo rayando al populismo.

De un período electoral al otro, como quien dice en lo que el hacha va y viene, una notable mayoría de ciudadanos no participa de las decisiones que los concierne y, por eso mismo, le corresponde el valor actual del término "idiota" con el que en Atenas se calificaba al hombre libre que no ejercía su derecho a participar en las actividades del Ágora.

Entretenidos los ciudadanos durante el proceso electoral y ajenos en lo sucesivo al funcionamiento de la cosa pública, nuestras democracias avanzan manipuladas hacia una casi perfecta ineptocracia. Exagerando por motivos argumentativos, esa es la tragicomedia que mejor caracteriza la democracia actual. Esta se avalancha hacia una perfecta descomposición y tiene, por único fin, el abismo de su propia superación en el pedestal de frecuentes gobiernos cada vez más autoritarios, erráticos, ineficientes, corruptos y ajenos a la verdad y al bien común. Mientras incompetentes eligen a sus pares, igualmente incapaces que ellos, los electos pasan a ofrecer soluciones no aptas a veces ni para ser experimentadas en un tubo de ensayo universitario.

c. Problema de civilidad. Dada esa pasividad e indiferencia ciudadana de inicio, fruto por excelencia de una formación ajena a la ética y al cultivado espíritu contemplativo y estético de cada ciudadano, este queda circunscrito y sumido en la "auto explotación" (Han 2012) de quienes solo tienen tiempo -no para sí mismos, sino- para subsistir o para trabajar y amasar fortuna en el mercado.

En ese contexto civilizatorio, conviene cobijarse en un espíritu cívico, y en un activismo tan democrático como republicano, oriundos de la tradición aristotélica ${ }^{3}$ difundida por Tocqueville (1835) y hoy día distintiva de Hanah Arendt (1972), pues se sustenta en el compromiso individual y colectivo gracias al cual la libertad humana jamás se extinguirá en el mundo político.

Pero, antes de llegar a ese fin, se impone asumir la renovada actualidad de la pregunta de Lenín (1981): “¿Qué hacer?” ¿Cómo superar un estado de cosas en el que cada día más ciudadanos taciturnos, desilusionados y alienados de la cosa pública malviven sosteniendo con su voto democrático a funcionarios que primordialmente encarnan el nefasto interés individual del "donde está lo mío", o cuando más, "lo mío y lo de los míos"?

\section{Los desafueros de la universidad}

a. La universidad dividida en sí misma. Una universidad no es una institución de lucro bajo el manto sagrado de la producción de profesionales. Ella trabaja en el ámbito de las ideas que, por axioma académico, forman a cada individuo e impactan en el porvenir de nuestras sociedades y -hasta ahora- del planeta tierra.

El sistema de educación superior universitaria resulta ser la madre fecunda que concibe recursos humanos idóneos, no solo a la educación preuniversitaria, sino al aparato productivo y de gobernanza de empresas, instituciones y de toda la sociedad. De ahí que en su célebre ensayo: La idea de una universidad, John Henry Newman (1900,

3 Ver, las dos obras fundamentales de Aristóteles (1998 y 1999) a la raíz de dicha tradición. 
p. 25) trace una raya de Pizarro entre los distintos modelos académicos europeos y observe con flema de buen inglés: "... Si entonces se debe asignar un fin práctico a un curso universitario, digo que es el de formar buenos miembros de la sociedad..."

b. Finalidad de los estudios. En franca contraposición a la ingrata universidad deudora de Kant (2005) ${ }^{5}$ : dividida en facultades gozando de la debida libertad de cátedra, y en la que la razón de ser de cada escuela y programa no deja de ser especializar a sus integrantes en un área particular del saber o destreza; en la de Newman, a cada asignatura de una u otra carrera se le asigna un fin práctico: la formación del sujeto humano en tanto que miembro de un conglomerado social ${ }^{6}$.

Para alcanzar ese objetivo, el prelado inglés no apeló a la efervescencia de la universidad napoleónica - que años más tarde llegaría a América de la mano del Movimiento argentino de Córdova en 1910-; pero tampoco confundió la formación de buenos miembros de la sociedad con el mero ingreso de profesionales universitarios al mercado.

A su mejor entender, la deformación del individuo -circunscrito a su condición de profesional- era, tan innecesaria, como insuficiente, para dejar de ser un ciudadano ïdiota'ensimismado en su propia apetencia e intereses privados, desprovisto de una comprensión y compromiso con el todo (el bien común de la sociedad) antes que con lo particular (el bienestar individual de cada uno).

c. La causa común. En sociedades y Estados naciones como los nuestros -donde los humanos perdemos la memoria, mueren las librerías y abundan si acaso los tweets y las redes de opiniones, pululan las bancas de apuesta y loterías. En ellos constato que la previsión y la esperanza están al alcance del azar, al igual que la causa final de las cosas, incluyendo la del valor del dinero, la socialización del "teteo" y los colmadones, el placer del consumismo e incluso el de la sexualidad.

Se trata de un mundo de $\operatorname{cosas}^{8}$ e individuos aglomerados en los que hay que defender "a paraguazos" (Aizpún 2021) la educación y entonces rescatar al ser humano de su egoísmo natural y al estado democrático de todo lo cosificado en su tambaleante orden político.

d. Y la cuestión de fondo. Asumiendo que la fiebre, -aun si bien impregna de sudor la sábana-, la

4 Difícil esbozar aquí la idea central de Newman. El autor y cardenal inglés rechaza una concepción falsamente elitista de la universidad en la que simplemente se procura reproducir un modelo típico de 'gentleman' británico: líderes arrogantes que con aires de superioridad se dedicaran a ocupar los resortes del poder político, económico e ideológico. Por el contrario, la misión de la universidad, el objetivo 'número uno', es hacer un bien a los estudiantes formándoles de modo completo y capacitándoles para desempeñar sus tareas en la sociedad de la mejor manera posible. Para ello, toda Universalidad (términos que subraya viene de universal) tiene como fin la cultura intelectual: educar la inteligencia y acostumbrarla a razonar bien en las distintas materias, a alcanzar la verdad y saberla comprender; no tiene como fin la educación moral ni la producción mecánica ni un oficio determinado. Y, por eso mismo, el principio y fundamento de la formación universitaria: "The first step in intellectual training is to impress upon a boy's mind the idea of science, method, order, principle, and system; of rule and exception, of richness and harmony” (Newman 1900, p. 27).

5 Según Kant (2005); las citas siguientes son de la traducción de 1963) ha sido una buena iniciativa fundar la Universidad dividiendo el trabajo en Facultades. Estas Facultades se dividen en dos clases: tres superiores y una inferior. "Pues entre las Facultades superiores sólo se cuentan aquellas a cuyo respecto el gobierno mismo tiene interés en saber si sus enseñanzas son de tal o cual naturaleza, o si deben ser expuestas públicamente: en cambio aquella que sólo está para velar por el interés de la ciencia se llama inferior, porque tiene libertad para disponer a su agrado de sus proposiciones. Pero el gobierno tiene mayor interés en aquello que le procura una influencia más fuerte y duradera sobre las masas, y de esta índole son los objetos de las Facultades superiores. Por eso, el gobierno se reserva el derecho de sancionar él mismo las enseñanzas de las Facultades superiores y cede las de la Facultad inferior a la inteligencia propia de los especialistas" (1963, pp. 21-22). Ahora bien, al margen de los gobiernos en propiciar en tiempos modernos esa u otra división de las facultades, lo decisivo es la universalidad del conocimiento que asume como fin de las universidades se diluye, no obstante la libertad de cátedra que se mantiene en las facultades inferiores.

6 Newman insiste por encima de todo en rechazar una concepción utilitarista de la vida universitaria. Obvio, hay quienes insisten en que la educación universitaria esté limitada a un fin particular, entiéndase bien, teniendo como diana un resultado práctico y verificable. "This they call making Education and Instruction "useful," and "Utility" becomes their watchword". Según Newman, sin embargo, "útil' significa no solamente lo que es bueno sino lo que tiende a lo bueno o es el instrumento de lo bueno, y en este aspecto la educación liberal tenden a la constitución del sujeto que ha de conocer y desempeñarse en sociedad, es real y verdaderamente útil, aunque no sea una educación profesional. Este es su argumento central: "If then the intellect is so excellent a portion of us, and its cultivation so excellent, it is not only beautiful, perfect, admirable, and noble in itself, but in a true and high sense it must be useful to the possessor and to all around him; not useful in any low, mechanical, mercantile sense, but as diffusing good, or as a blessing, or a gift, or power, or a treasure, first to the owner, then through him to the world. I say then, if a liberal education be good, it must necessarily be useful too." (Newman 1900: Discurso VII, pp. 167 y ss.). Por supuesto, Newman no niega que la universidad haya de formar médicos, abogados, ingenieros, etc., pero insiste en que esa formación no puede estar orientada exclusivamente hacia dicha capacitación. Cuando se exige justamente ese deber contraído hay que insistir en que al perseguir exclusivamente la formación útil ni siquiera ese mismo fin se alcanzaría más que superficialmente.

7 Ver, Patiño (2018)

8 "Sólo los hombres, como mortales, alcanzan habitando el mundo como mundo. Sólo aquello del mundo que es de poca monta llegará alguna vez a ser cosa", Heidegger 1954: 65. 
padece el cuerpo social, en lo sucesivo no se trata como pretende el espíritu nominalista de sustituir una narración por otra y solventar entonces la deficiencia de ciudadanía presente en la carátula misma de la democracia representativa. Urge refundar tanto a los estados republicanos como a los pueblos y sus naciones en algo más estable y promisorio que el interés naturalmente egoísta de cada individuo, sea este o no profesional.

Pero, ¿por qué los ciudadanos no dejan atrás su déficit de ciudadanía y superan así su propio nivel de pasividad en el foro público?

\section{Los estudios propedéuticos}

a. Asunto de énfasis. Empleo el término "estudios generales" como sinónimo de estudios propedéuticos. Con ello no pretendo soslayar ni ignorar que, en la tradición antillana, sobre todo desde la segunda década del presente siglo, se impone la concepción de Rodríguez Beruff (2010: a y b), entre otros ${ }^{9}$, en el sentido de que los cursos de educación general no pretenden remediar ni nivelar competencias desiguales del estudiantado y tampoco hacer las veces de introducción a disciplinas específicas ${ }^{10}$.

Los estudios iniciales, propedéuticos o -en su acepción más usual de- generales se han convertido en nuestras universidades a lo largo y ancho de gran parte del hemisferio americano en paliativos a las sensibles deficiencias en la formación preuniversitaria de los estudiantes. Por ese motivo constato que, de hecho, sus asignaturas se combinan en un híbrido que termina intentando ser un antídoto y a lo más un barniz de cultura general epidérmico y puesto en el pénsum sin relación con los subsiguientes programas de estudio y, aun menos, con el pretendido desempeño profesional de cada egresado.
La principal y más significativa de esas fallas -por supuesto, sin contar aquí con la de la educación familiar- es no haber cultivado la humanidad del subiectum de uno mismo. La envergadura de tal anomalía -por carecer cada uno de subjetividad y civilidad- termina siendo incluso más fundamental y crítica que los vergonzosos e hirientes yerros de lectura, escritura, comprensión, matemáticas, lógica, historia, apreciación estética, científica y manejo tecnológico. Resulta ser que, así como sin recipiente donde contener un líquido, este se desparrama, por igual, sin la constitución y contención del sujeto humano, imposible que cualesquiera sea la modalidad educativa recibida, alguien inconsistente pueda retenerla y beneficiarse de ella.

b. El subiectum del sujeto humano. Por consiguiente, la misión de los estudios generales, más que la de revestir de propuestas y destrezas tecnológicas al individuo, es la de cultivar y desarrollar en cada estudiante sus sentimientos, afectos y emociones hasta convertirlos y hacerlos cónsonas con mejores patrones de comportamiento cultural y óptimas prácticas cívicas y de apreciación estéticas.

A todas luces, en contextos donde las tensiones sociales vienen abonadas por la falta del debido marco de referencia y desarrollo emocional del foro interno de cada uno, la labor académica de dichos estudios propedéuticos deviene casi imposible. Vivimos autoexplotándonos, con el pie puesto en el acelerador. En especial, a la hora de soslayar la humanidad de cada uno de nosotros y apresurarnos a mantener el ritmo con el que aparecen en el mercado los frutos de la revolución científico-tecnológica'11.

Por eso, me atrevo a decir que el tiempo se acelera debido al efecto de la "Reina Roja" (Ridley, 1993),

9 A modo de ejemplo ver las contribuciones de Vélez y Subirats, 2010, pp. 17-20; Taveras y Olivo, 2010, pp. 25-29.

10 La posición del eminente académico centra su atención en cinco elementos fundamentales: la relación de los estudios generales con otros niveles educativos, la articulación de esos estudios en la estructura curricular universitaria, las formas organizacionales de los estudios generales, los mecanismos para lograr su renovación constante y a relación entre los estudios generales y el desarrollo humano (ver, Rodríguez Beruff 2010ª, p. 17). Su enfoque es válido e indispensable, a pesar de no partir de lo que tengo por principio y fundamento de cualquier elemento: la constitución del sujeto humano en tanto que depositario, tanto de esos estudios generales, como de otros más específicos a una u otra especialidad.

11 Pero, atención, la velocidad de la vida no es del todo nueva. Ya en 1930 el economista John M. Keynes opinaba lo que ahora suele visualizarse como el pan nuestro de cada día: "Por primera vez desde su creación, el hombre se enfrentará a su problema real y permanente: cómo utilizar su libertad de las preocupaciones económicas apremiantes, cómo ocupar el ocio, que la ciencia y el interés compuesto le habrán ganado, vivir sabiamente. y agradable y bien" 
según el cual -desde una perspectiva evolutiva- la vida en la tierra debe competir para mantenerse viva. Los depredadores y las presas están en una carrera sin fin para desarrollar nuevas habilidades y evitar la extinción. Los conejos que desarrollan orejas más largas para escuchar a los zorros sobreviven más. Los zorros que desarrollan patas más fuertes para correr más rápido capturan más conejos y no mueren de hambre. Y así evolutivamente en lo sucesivo, hasta el infinito de un Omega que no se avizora de no ser por el cambio climático.

c. El dataísmo. En cualquier escenario, a tal punto ha llegado dicha vorágine que ya no se habla como hace apenas tres décadas de la sociedad de la información, de la comunicación y de la inteligencia, sino de la desinformación, la post verdad y el fake news; y de esto último tanto como de la futurible inteligencia artificial y del Homo sapiens de antaño. El dataísmo que separa al Homo sapiens de su destino se alza como raya de Pizarro entre ambas versiones de la realidad ${ }^{12}$.

De acuerdo a autores como Harari (2011) ${ }^{13}$ y, sobre todo Byung-Hul Han (2012), el dataísmo es una forma de conocimiento que con su cálculo analítico anula el pensamiento humano.

No existe un pensamiento basado en los datos. Lo único que se basa en los datos es el cálculo... Los macrodatos hacen superfluo el pensamiento porque si todo es numerable, todo es igual... Estamos en pleno dataísmo: el hombre ya no es soberano de sí mismo, sino que es resultado de una operación algorítmica que lo domina sin que lo perciba. (Rendueles, 2020).

He ahí la contra-inteligencia de sí misma, esa que no se enfrenta regresando al paraíso terrenal ni buscando refugio saliéndonos de las redes sociales fuera de la cueva de Platón. A ese propósito reflexiona Han,
No podemos negarnos a facilitarlos: una sierra también puede cortar cabezas... Hay que ajustar el sistema: el ebook está hecho para que yo lea, no para que me lea a mí a través de algoritmos... ¿O es que el algoritmo hará ahora al hombre?... Necesitamos una carta digital que recupere la dignidad humana y pensar en una renta básica para las profesiones que devorarán las nuevas tecnologías. (Han en la entrevista concedida a Rendueles, 2020).

\section{d. Lo humano de los humanos y el papel de la} universidad. A la luz de lo que precede, el reto consiste en reconocer la idea del bien y adentrarnos entonces en la oscura espesura de una fosa de pre-juicios, credos y opiniones con el propósito final de rescatar a un sinnúmero de cautivos igualdados por la ignorancia y la cacofónica repetición de afirmaciones sin pruebas que la avalen. El mundo de la "re vera" es mucho más que data, mercadeo y algoritmos. Para reconocerlo y admirarlo se requiere que la especie humana sea reconocida por lo que ella es -humana- gracias a seres libres, pensantes, contemplativos y solidariamente éticos.

Para lograrlo, las universidades, y a la cabeza sus sistemas de estudios propedéuticos, tienen que replantear su pedagogía, objetivos educativos y los currículos que proponen. Se requiere más importancia a la formación ética y estética de cada uno de los estudiantes sin excepción. Formación esa orientada al desarrollo del sentido práctico del bien, de la solidaridad a ultranza y de la belleza de todo, como conditio sine qua non para darle consistencia y profundidad al sujeto humano en tanto que dotado -a modo de sustrato a uno u otro adiestramiento y profesión- de la conciencia de ciudadanía requerida para el buen funcionamiento de la vida política en común.

De no materializar ese fin, empero, seguirá guardando toda su relevancia la aseveración de Antonio Gramsci a mediados del siglo pasado. A

12 (Citado en ICHI PRO, s.f.). En la actualidad, el historiador israelita Yuval Harari (2011) al recapitular su breve historia del Sapiens advierte que este semidiós ni siquiera sabe hacia dónde va. Los cambios hoy día son tan vertiginosos que ni siquiera estamos en capacidad de caerle atrás a tantas y tan profundas transformaciones.

13 Para Harari, un dataísta es alguien que, a la hora de exponer y tomar decisiones, se fía en los macrodatos y en los algoritmos computacionales más que en el sentido común, el conocimiento y la sabiduría humana. Según explica en su obra Homo Deus: Breve historia del mañana (2015), el datismo o dataísmo es un término empleado para referirse a la mentalidad -no religiosa, sino filosófica- propiciada por la inteligencia artificial y la acumulación de datos o big data; mientras que el dato es una representación simbólica -numérica, alfabética, algorítimica, espacial o de otra modalidad- que describen e implican hechos empíricos, sucesos o entidades. 
modo de obertura a aquel estado de idiote ${ }^{14}$ del que se habló anteriormente:

Lo que ocurre, el mal que se abate sobre todos, no se debe tanto a la iniciativa de los pocos que actúan, como a la indiferencia de muchos (que desconocen que) quien verdaderamente vive no puede dejar de ser ciudadano ni de tomar posición. (Gramsci, 2017).

Como forma de romper la inercia del conformismo, la educación superior universitaria no puede seguir dependiendo de la transferencia y atiborramiento de datos, cálculos, teorías, leyes naturales o normas sociales y morales al estudiantado. La simple acumulación de conocimientos más o menos especializados está mejor dotada y es más fácil de adquirir a la vuelta de la esquina en cualquier centro de datos, biblioteca digital y computadora provista de más memoria, información y capacidad de análisis que la de cualquier cerebro humano.

En lo adelante, se trata de diferenciar un tipo de aprendizaje que privilegia la acumulación de "facts" e información -para dotar al estudiantado de destrezas y capacidades, del rescate de la humanidad de nuestro ser, de su capacidad no solo racional sino también afectiva, debido a su conciencia, voluntad y comportamiento cívico y democrático.

En ningún contexto aparece tan evidente ese desafuero como en el ámbito de la democracia, debido al inútil esfuerzo unitario de lustrar con barniz las conciencias estudiantiles; como si el hábito hiciera al monje. La costra de abulia, desinterés, indiferencia e inactividad cívica que desde la perspectiva griega envuelve a un número significativo de conciudadanos en nuestros regímenes electorales y representativos no se subsana con una educación formalmente preocupada en adiestrar al estudiantado para integrarlos como competitivos y valiosos profesionales en el mundo laboral.

Pero no por tal desafuero minimicen el inquebrantable vínculo entre universidad y democracia. La educación universitaria es hoy por hoy la columna fundamental de la cultura democrática, pues sus estudios generales son el pilar para remover la poltronería ciudadana. En efecto, si la educación universitaria y sus estudios propedéuticos formaran a sujetos libres y con valores éticos y estéticos de raigambre democrática no habría razón humana capaz de explicar el status quo tambaleante de nuestras alegadas democracias en buena parte de todo el hemisferio americano. Y mucha atención, digo tambaleante porque hoy día basta una burda falacia argumentativa como las de cualquier mandatario -tipo Donald J. Trump (2016-2020)para confundir el día y la noche, la vida y la muerte, la victoria y la derrota, los otros y los peores.

\section{Conclusión, a propósito de la de- mocracia occidental y los desafueros universitarios}

a. Pedagogía y estudios generales. La atención pedagógica de los estudios propedéuticos ha de estar concentrada prioritariamente en la constitución y formación del subiectum humano y, de acuerdo con la tradición del cardenal Newman, en el sentido de "formar buenos miembros de la sociedad", en hacer las veces de contrapeso al interés profesionalizante que hoy por hoy predomina en la mayoría de las universidades hemisféricas.

En ese propósito se descubre el principio y fundamento de los estudios propedéuticos, pues se trata de un contexto en el que es imposible exculpar de responsabilidad a las universidades por lo errático de su ejercicio de ciudadanía e institucionalidad democrática. Imposible exculparlas, dado que el $100 \%$ de los profesionales de nuestras sociedades y, para colmo, un prácticamente absoluto número de funcionarios estatales y directivos en general son egresados de las aulas universitarias y son ellos precisamente quienes toman, ejecutan, supervisan y califican pletóricas decisiones de claroscuras y desilusionantes incidencias a todos los niveles de nuestra vida en sociedad. ¡No que todo sea malo, pero sí que todo es mejorable!

A la luz de aquel propósito y de ese contexto de corresponsabilidad sostengo que, para que los estudios propedéuticos logren su objetivo de formación, deben adoptar una perspectiva holística del ser humano y reintroducir la (re)-(flexión) cívica, ética, estética e histórica en la ecuación pedagógica de los procesos de enseñanza-aprendizaje. 


\section{b. Los estudios generales como vínculo de} ciudadanía responsable. Ahora bien, "el" mínimo común denominador de todos esos universitarios es que, independiente de su profesión y ocupación laboral, todos, sin siquiera una excepción, han cursado los estudios generales de una o más de las instituciones de educación superior en el país o en el exterior.

De ahí que -asumiendo la antedicha perspectiva holística y la reflexión como norma pedagógica de empoderamiento subjetivo de lo real e imaginario y conceptual- esta es mi tesis y dos de sus corolarios:

Tesis. Los estudios generales universitarios son el punto de apoyo necesario para la formación del subiectum humano de cada uno de los estudiantes y, por vía de consecuencia en el futuro inmediato, la remoción y transformación del ejercicio de ciudadanía practicado, tanto por los representantes electos y funcionarios públicos designados, como por el conglomerado de conciudadanos predominantes en nuestros más diversos regímenes políticos en la actualidad.

Y, por tanto,

Primer corolario. Los estudios generales tienen que hacer las veces de contrapeso al impulso profesionalizante que hoy predomina en las universidades, de manera que equilibren el objetivo socioeconómico de la educación haciendo valer su misión de formación del sujeto individual y ciudadano de cada estudiante, so pena de que la vida en sociedad termine siendo ingobernable en sentido democrático y corrupta debido a su propia desintegración.

Segundo corolario. Para que los estudios generales logren su objetivo fundamental, deben adoptar una perspectiva holística del ser humano y reintroducir en la ecuación de los procesos de enseñanza - aprendizaje las dimensiones cívicas, éticas y de contemplación anteriormente advertidas.

c. Soluciones. Amparado por ese marco de referencia conceptual, respondo a modo conclusivo tres preguntas cruciales a la transdiciplinaridad de los estudios generales, al ejercicio de la ciudadanía y al Estado de derecho democrático y social:

c.1 ¿Qué hacer para superar desde el ámbito académico un estado de cosas en el que los ciudadanos se desviven y malviven sosteniendo con su voto a funcionarios que representan su misma ineficiencia y desinterés por el bien común, mientras prima solamente el interés individual de lo mío?

Respuesta: podar y rediseñar el currículum propedéutico del 'laborantismo' de cursos y créditos yuxtapuestos en nuestras universidades e imponer como norma pedagógica la actividad reflexiva, pues solo la reflexión constituye al sujeto humano sin solipsismo alguno de un yo privado de lo demás, en la medida en que se ejercita edificando su intimidad en y desde fuera de sí mismo.

Desde mi perspectiva, es suficiente con que ese rediseño curricular fuera concebido a partir de este ABC tan didáctico como reflexivo: lectura, expresión escrita y debate. En concreto,

A: Lectura de historia y de literatura universal, clásica y contemporánea, incluyendo la relación de las más notorias ideas científicas, las sociales y las humanistas;

B: Escritos de comprensión e interpretación de lo leído a lo largo del propedéutico y preferiblemente de los estudios de grado; y,

C: Debate e intercambio continuo sobre lo aprendido y practicado.

c.2 Segunda pregunta, ¿cuál tiene que ser la piedra angular de cada ciudadano y profesional en formación a la hora de enmendar y promover nuestros actuales sistemas alegóricamente democráticos?

Respuesta: la conciencia cívica, pues solo ella, en tanto que reflexiva, es capaz de hacer de bisagra democrática -entre lo que sabe y lo que hace- de conformidad con las ideas y los valores que la animan en y con sus connaturales.

Así, pues, el quid universitario de esa formación de la autoconciencia cívica no es solo que cada uno adelante sus legítimos intereses como profesional por "amor propio" (Smith, 1790)15, sino que -como ciudadano- haga valer de forma mancomunada

15 Ver, Concepto clave de Adam Smith, 1790 -en particular Parte I, $1^{\text {a }}$ Sección- para entender posteriormente el fundamento de la acumulación de riquezas, no solo de las naciones, sino de los individuos. 
patrones de comportamiento, ideas, apreciaciones y valores como el del bien común -todos de complexión democrática.

En la medida en que se desarrolle la conciencia cívica de cada estudiante universitario y se aproxime al sitial del ideal antillano de "ser justos" (J.P.Duarte") -de acuerdo a principios éticos y razonables- "con todos y para el bien de todos" (José Marti), la hoy día soluble conciencia de nuestros congéneres podrá ulteriormente aprender y desenvolver sus conocimientos y habilidades en uno u otro campo profesional, pero siempre bajo el lema del "Magis" (Ignacio de Loyola) que todo lo encauza a hacer siempre y en todas las cosas más y mejor.

\section{c.3 ¿Por qué concebir y valorar los estudios} propedéuticos en nuestras universidades?

Respuesta: su valor es tanto más indispensable cuanto que la vida humana no transita en solitario ni con la precisa rigidez con que se explaya un algoritmo.

Suele decirse que en sus días Albert Einstein advirtió que no es suficiente enseñar a los hombres una especialidad. Con ello, se le atribuía decir, que se convierten en algo así como máquinas utilizables, pero no individuos personales válidos. Para ser válido el hombre debe sentir intensamente aquello a lo que puede aspirar. Tiene que recibir un sentimiento vivo de lo bello y de lo moralmente bueno. Caso contrario, por vía de consecuencia, el individuo humano se parecería más a un perro bien amaestrado en medio del reino animal que a un ente armónicamente desarrollado en "el reino de este mundo"16 en el que se aglomeran sus semejantes.

Independientemente de la originalidad o no de aquella afirmación atribuida al genial profesor e investigador universitario, premio Nobel de Física, nuestro papel como académicos y docentes e investigadores a nivel de estudios generales es y sigue siendo formar, antes que profesionales in fieri especializados con ojerizas en una sola disciplina y quehacer, estudiantes conscientes de sí gracias a una reflexión formativa, tan democráticamente cívica y responsable, como personalmente humanizante.
Exclusivamente a partir de ahí, cada sujeto atento a la universalidad del saber, podrá revestirse del hábito de una u otra profesión.

c.4Mas simás allá de quéhacer alguienaún pregunta: ¿cómo lograrlo?, no dude en respondérsele: por medio de la constitución del subiectum humano que busca su felicidad como ciudadano responsable del estado de cosas democráticas en el que se encuentra inmerso y desde el cual está llamado a desenvolverse y desarrollarse -no como Robinson Crusoe, aislado en una isla junto a Friday, su esclavo, sino- conjunta y equitativamente con todos los otros conciudadanos.

$\mathrm{Ni}$ la universidad ni sus estudios generales deben tener algo que ver con el novelesco personaje de Defoe (1994), desamparado como fuera ya escrito en una isla y acompañado de su esclavo. Y para que ese no sea el final que nos depara el derrotero democrático, permítaseme, una exhortación final.

No dejen y no dejemos de reflexionar y volver a responder las preguntas que anteceden las tres respuestas anteriores. Pero más aún, renueven y renovemos el firme propósito de no eludir las responsabilidades y consecuencias de todo lo que hacemos o dejamos de hacer en aras del espíritu democrático de nuestros respectivos estudiantes, de la patria y de nuestra civilización.

d. Incógnita conclusiva. Temo formular la conclusión a todo lo expuesto. Algo me dice que en la academia -al menos la occidental en nuestra longitud- nos hemos acostumbrado al "happy ending" y a la resignación. No obstante, terminaré sin este ni aquella.

d.1 El final feliz es feliz, porque se vende bien. Como la imagen de las mejores y a veces más publicitadas universidades. Sin embargo, en ese contexto surgen dos preguntas que, por más claridad conceptual que se tenga en países como los que nos duelen en "nuestra América" (José Martí), tienen que ser despejadas.

La primera de esas dos dudas propias a cualquier espíritu escéptico es esta: asumiendo que lo dicho anteriormente -o incluso algo más sensato y enjundioso- sea bueno y válido, ¿cómo "re"-formar 
unos estudios propedéuticos que a todas luces lucen un pastiche de remilgos yuxtapuestos más que algo bien formado y más formativo?

Huelga decirlo, mientras no se discierna el valor y la coherencia interna de los estudios generales, se está -no condenado, pero sí en camino- a malgastar horas y más horas -de esta, aquella y la otra comisión de más allá, amén de consultores y expertos internacionales contratados por facultades y rectorías- antes de someter a los consejos universitarios novedosos planes de estudio cuyas posibilidades de incidencia en la forja de mejores ciudadanos -y por añadidura, profesionales más sobresalientes- tienen una alta probabilidad de no superar el diagnóstico sociopedagógico del 'más de lo mismo'.

La razón de tal infecundidad debe ser advertida cuantas veces novedosas iniciativas de modificaciones y actualizaciones curriculares no toquen el mal de fondo. Y ni lo ciernen ni lo disciernen, pues más bien lo eluden, multiplican y perpetúan cuantas veces las aulas y los laboratorios -exagerando por motivos didácticos- se engalanan de innovaciones que automatizan y homogenizan el acto de enseñanza-aprendizaje, soslayando con buenas propuestas y excelentes intenciones al supuesto beneficiario final: el sujeto humano, cada uno tan diverso del otro como las huellas digitales de sus respectivos dedos lo son entre sí mismas.

d.2 Por consiguiente y concluyo, es menester hacer un alto para no desconocer lo evidente y caer, no necesariamente, en la frustración, pero por lo menos sí en la resignación de la conciencia estoica.

Parar y dejar de apelar a lo que hacemos soportando el deterioro de la práctica democrática y el ensimismamiento de los valores y objetivos profesionales conviene responder con la sinceridad, entusiasmo y espontaneidad de los años mozos la última pregunta: ¿será posible evitar que el tiempo se escurra de la base de nuestros sistemas fundamentales de enseñanza-aprendizaje como lo hace el agua de las manos que pretenden retenerla? ¿Cómo personalizar -de manera individual- la educación propedéutica universitaria de forma tal que, asumiendo como encargo la era de la enseñanza universitaria democratizada, cada quien reciba el pie de amigo y atención que él y solo él en tanto que ser único, amerita?

Téngase en cuenta la envergadura del verdadero dilema prometeico enfrentado en la actualidad.
Así como dos más dos no son automáticamente cuatro, pues el resultado depende siempre del valor de la unidad que se adiciona, lo mismo acontece en un ambiente universitario donde cada ser humano ahí presente no es la simple adición de otro por obra y gracia de algún algoritmo o proceso estereotipado, automático o mecánico. Ante cada sujeto humano singular, no obstante ser tenido como imprescindible dada la cantidad de personas a educar. La necesidad de uniformar los procesos pedagógicos, empero, no está a la medida de la suficiencia y menos de la calidad educativa en el altar de la educación de entes todos y cada uno de ellos únicos y singulares.

d.3 De ahí la disyuntiva final de la que hay que escapar para no permanecer en el escepticismo discreto y menos aún en el conformismo del "no hay otra alternativa". Sí, sí existen mejores alternativas para que los estudios universitarios justifiquen su impacto positivo en cada subiectum humano con sentido personal y social. La mejor de ellas está atada al proceso propedéutico del ensayo y error de las ciencias básicas.

El diagnóstico universal es el mismo: la conciencia cívica del estudiantado universitario dista aún de ser dominante y los estudios profesionalizantes ni la ayudan ni se benefician de ella. Pero el solo nombramiento de comisiones no es la solución, menos aún la resignación. Hay que seguir machaconamente, a tiempo y a destiempo, predicando con los hechos en el aula y ante la atención e interés de cada estudiante. Probando y corrigiendo, con el cuidado del orfebre frente a cada joya. Si a nadar se aprende nadando, durante el transcurso en los Estudios Generales, cada sujeto en disposición de aprender es el que ha de formarse, como en la mejor usanza artesanal, esculpiendo su conciencia, su voluntad y su inteligencia de la mano del maestro pedagogo.

Ante esa única realidad prometedora, me temo que la luz al final del túnel llega de la mano de ese ensayo y error constante capaz de sacar lo mejor de cada uno durante su formación. Y eso, en definitiva, lleva a otra la dimensión postrera de la misma cuestión. Me refiero a la contramoneda del educando, al cuerpo particular de docentes, usualmente minosvalorados en la dinámica administrativa de la enseñanza.

Sin embargo, en la medida que el valor de la enseñanza universitaria -tanto la propedéutica, 
como la de las facultades- no es superior al de su cuerpo de docentes, la concepción y la reforma de los Estudios Generales depende por igual del espíritu pedagógico de estos. Ellos, sin confundirse, pero también sin separarse de cada cohorte agrupada de estudiantes, son el principio de la realidad que de manera no mecanicista y aún menos masificada impone el ritmo de desenvolvimiento de la relación personal entre ese profesor y ese aspirante a superarse a sí mismo como ciudadano, como profesional y como ser humano.

El cimiento del futuro depende no de incuestionables planes y proyectos preestablecidos, que devienen normativos por falta de saberes y la fuerza de los hechos administrativos y financieros. Nada de eso, está marcado solamente de los ires y venires que germinen a partir de esa relación primaria -docente pedagogo / ciudadano estudiante- en la que se actualiza y renueva la enseñanza-aprendizaje que comienza con cada sujeto humano que cursa Estudios Generales en un medio ambiente más realista, promisorio y democrático para todos.

\section{Referencias bibliográficas}

Aizpún, I. (2021). 20 mil millones de dólares después...; en, Diario Libre, 7 de abril 2021.

Arendt, H. (1972). Crises of the Republic: Lying in Politics; Civil Disobedience; On Violence; Thoughts on Politics and Revolution. Harcourt Brace Jovanovich

Aristóteles (1998). Política. Alianza.

Aristóteles (1999). Ética a Nicómaco. Madrid, Centro de Estudios Políticos y Constitucionales.

Carpentier, A. (2015). El reino de este mundo. Espasa Calpe.

Defoe, D. (1994). Robinson Crusoe, edited by Michael Shinagel. (original 1719).

De Tocqueville, A. (1835). De la démocratie en Amérique, vols. I \& II (1st ed.). Librairie de Charles Gosselin.
Gramsci, A. (2017) Odio a los indiferentes. https://www.resumenlatinoamericano. org/2017/12/21/un-texto-de-gramsci-degran-vigencia-odio-a-los-indiferentes/

Han, B. (2012). Transparenzgesellschaft. Matthes \& Seitz, Berlin. (Edición en castellano: La sociedad de la transparencia. Herder Editorial, 2013).

Harari, Y. (2011). Sapiens: De animales a dioses, Debate, 2011.

ICHI PRO (sin fecha): Director de ingeniería de Google: así de rápido cambiará el mundo en diez años. Ver, https://ichi.pro/es/director-de-ingenieria-de-google-asi-derapido-cambiara-el-mundo-en-diezanos-122176338088820

Kant, I. (2005). Der Streit der Fakultäten. Hrsg. von Horst D. Brandt und Piero Giordanetti, Felix Meiner Verlag, Hamburg (Philosophische Bibliothek 522). (Versión en castellano: El conflicto de las facultades. Editorial Losada, S.A., 1963).

Lenín, V. (1981). ¿Qué hacer?, en Obras completas, vol. VI. Editorial Progreso.

Maquiavelo, N. (1999). El Príncipe. Editado por el Aleph.com; https://ocw.uca.es/pluginfile. php/1491/mod resource/content/1/El_principe Maquiavelo.pdf

Mejía, M. (2021). "Al 68\% de la gente en RD no le importaría tener gobierno no democrático. Informe del PNUD alerta que la democracia está en crisis en la región"; en, Diario Libre, 23 de junio 2021. https://www.diariolibre. com/actualidad/al-68-en-rd-no-le-importariatener-gobierno-no-democratico-EA270513068 \% de la gente en RD no le importaría tener gobierno no democrático

Patiño, P. (2018). "El «Movimiento de Córdoba» y su efecto en la universidad latinoamericana"; en, https://www.universidadsi.es/elmovimiento-de-cordoba-y-su-efecto-en-la-universidad-latinoamericana/ 
Rendueles, C. (2020). "Entrevista a Byung-Chul Han". El País, 15 y 17 de mayo. https:// elpais.com/cultura/2020/05/15/babelia/1589532672_574169.html

Ridley, M. (1993). The red queen. Sex and the evoIution of human nature. London, Viking. https:// docs.google.com/viewer?a=v\&pid=sites\&srcid=ZGVmYXVsdGRvbWFpbnxwYWRvbGluYWdlbmV0aWNzfGd4OjUyN2MOYjAzNjA1ZWZhZDE

Rodríguez Beruff, J. (2010a). La pertinencia y actualidad de los Estudios Generales; Conferencia Inaugural en el Simposio sobre "Los Estudios Generales en la región latinoamericana", Pontificia Universidad Católica del Perú, Lima, Perú, 15-17 de septiembre de 2010. https://www.academia. edu/6390094/La pertinencia y actualidad de los Estudios Generales

---(2010b) Los estudios generales en la Universidad de Puerto Rico: notas sobre un cambio curricular. Cuaderno de Pedagogía Universitaria, 7(14) 6-10. https://www. pucmm.edu.do/publicaciones/Documents/ cuadernopedagogia/CuadernodePedagogiaNo14.pdf

---(sin fecha) Los estudios generales: un movimiento transatlántico; en, http://universalia.usb.ve/node/605
Newman, J. (1900). The idea of a university. Longmans, Green, version original de 1878. Versión en español. Discursos sobre el fin y la naturaleza de la educación universitaria. Eunsa, 1996).

Smith, A. (1790). The Theory of Moral Sentiment. MetaLibri, 6a. edición, 1790: Parte I, 1a. Sección, pp. 4-21; ver, https://www.ibiblio.org/ $\mathrm{ml} /$ libri/s/SmithA MoralSentiments p.pdf\#: :text=The\%20Theory\%20of\%20Moral\%20 Sentiments $\% 20$ Adam $\% 20$ Smith $\% 20$ with,imagines\%20should\%20be\%20the\%20 sentiments\%20of\%20the\%20sufferer

Taveras, L. y Olivo, R. (2010). Estudios Generales: el qué y el para qué. Apuntes para una reflexión; en PUCMM: Cuaderno de Pedagogía Universitaria, 7(14) 25-29. https:// www.pucmm.edu.do/publicaciones/Documents/cuadernopedagogia/CuadernodePedagogiaNo14.pdf

Vélez, W. y Subirats, P. (2010). Apuntes para un perfil del profesor o la profesora de Educación General; en PUCMM: Cuaderno de Pedagogía Universitaria, 7(14) 17-20. https://www.pucmm.edu. do/publicaciones/Documents/cuadernopedagogia/CuadernodePedagogiaNo14.pdf 